\title{
Writing Strategies for Graduate Students
}

\author{
Jennifer L. Craig \\ Department of Aeronautics and Astronautics/Program in Writing and Humanities \\ Massachusetts Institute of Technology
}

\begin{abstract}
Most graduate students at the Department of Aeronautics and Astronautics at the Massachusetts Institute of Technology experience little difficulty in writing their theses; however some students struggle to articulate their ideas. This struggle can include issues of scope, focus, conciseness and coherence, use of technical graphics, use of graphics, and grammatical and syntactical errors. When this happens, thesis advisors can find themselves coaching graduate students in writing skills while also responding to the technical content. This paper discusses some common problems of graduate student writers and suggests a model that can facilitate the thesis writing process with an efficient and effective use of thesis advisors' time.
\end{abstract}

\section{Introduction and background:}

Not all graduate students are well prepared to write the master's or the doctoral thesis nor do they approach the task effectively. Although most students at the Department of Aeronautics and Astronautics at the Massachusetts Institute of Technology experience little difficulty, others struggle to articulate their ideas. When this happens, their advisors who work with them on technical content also find themselves coaching their students in writing skills. Generally this is not an optimal use of the advisors' time nor is such intervention always successful. While it may iron out simple errors, it's rarely sufficient to make the student a significantly better writer or to improve large structural errors in a thesis. In addition, writers who have been poorly prepared at the undergraduate level or for whom English is not the first language may experience more confusion and frustration in the final writing stages.

This paper describes work that began at the University of Maine, Orono, in 2001 in the Computer Science department graduate program and in the Department of Electrical Engineering capstone course. The paper describes some common writing difficulties and suggests a writing model that can address some of the more common problems, thus helping a range of graduate students to write their theses more efficiently and effectively.

\section{Some common problems in writing the graduate thesis and their sources:}

Some common problems in graduate student writing include difficulty in focusing the scope of the research; lack of conciseness and organization in the writing; unfamiliarity with academic writing style; unevenness between the thesis sections; graphics that are inappropriate, too few or too numerous, and/or not skillfully interpreted; and sentence level errors (spelling, punctuation, usage, grammar). Often, corrective attempts to 
improve graduate student writing focus chiefly on the latter category: sentence level errors.

But although advisors and students often categorize the difficulty as simply "bad writing," writing problems in the thesis can be traced to several sources. Understanding these sources can help prevent or resolve difficulties. First, with unsuccessful writers, we often discover that the writing process is "back loaded." The discussion and research has gone forward, but very little has been written until close to the end of the process. Since articulation and thinking are interdependent, this often means that students have delayed their effort to express their thoughts clearly until late in the process. This delay adds pressure to the writing process. More disturbingly, when the writing is produced, both advisor and student may discover gaps or inconsistencies in the student's work.

Second, when the writing process is left until very near the end, it means that the writing tasks have been separated from the cognitive tasks. Thus, the writing becomes an artifact of a task that was accomplished months before and perhaps is no longer the focus of immediate interest or attention.

Third, unsuccessful writers often have not allowed enough time to complete the writing. They underestimate how long it takes to clearly articulate ideas and to write them coherently and correctly.

Fourth, we sometimes discover that the unsuccessful writer is an international student who not only has not prepared a complex document like a thesis before but also has not done it in English. S/he may have language skills that are entirely sufficient for her/his coursework and professional interaction but that are not strong enough to prepare a large, formal thesis easily. Alternately, the writer may have been poorly prepared at an undergraduate level and is unsure about basic writing practices.

Inarguably, the thesis in engineering---at both the master's and the doctoral level--- is a complex technical writing task. As a document, a thesis requires writing that is precise, accurate, complete, and organized. Moreover, a thesis must also argue for the significance of the research, the credibility of the methods, and the implications of the results. A thesis must adhere to academic style and structure. In addition, the style and structure of a graduate thesis and even the rhetorical strategy are often heavily influenced by cultural expectations and practices as well as disciplinary criteria. Lastly, most writers are unlikely to write more than one or two of these documents, so experience cannot help them.

Yet even though the thesis is a complex technical task, it can be guided by three basic principles that guide all successful writing. First, writing (as well as spoken communication) is practice-based. In other words, there is no other way to become adept at writing other than to write. It's also through writing that we learn to articulate our thoughts clearly; our critical thinking is strengthened and clarified by our expression of it in writing.

"Proceedings of the 2005 American Society for Engineering Education Annual Conference \& Exposition Copyright (C2005, American Society for Engineering Education” 
Second, successful complex documents are iterative, building in successive stages. Successful writing begins with a planning, focus, and organization stage in which the writer spends time defining the scope of the writing, organizing his/her thoughts, and obtaining the necessary information about which $\mathrm{s} / \mathrm{he}$ wants to write. The planning stage is logically followed by a stage in which thought is developed and supporting evidence is marshaled. Experienced writers quickly grasp that these two stages are not discrete. The third stage, however, is most effective when it is discrete. In this third and last stage of a document, writers review for technical accuracy, correct the language at a sentence level, and then attend to the final editing, revision, and proofreading.

And lastly, different writing tasks are more effective when they're linked to the appropriate stage of writing and to the cognitive tasks within that stage. For example, a section establishing background and significance can be written early in the project when it is foremost in the graduate student's mind. Again, it's more efficient to write a literature review when the student is actually reviewing the literature.

The discipline of teaching writing offers suggestions for addressing common graduate student writing problems. What follows is a practice-based model that organizes these suggestions in a way that optimizes the thesis advisor's time and uses it appropriately while prompting students to prepare successful theses.

\section{A suggested model:}

Generally, unsuccessful thesis documents result from the "back loaded" model in which not much focused writing takes place during the first months (or years) of the graduate work until---several months before the submission of the thesis---the student begins to think about writing his/her thesis. In the following sections, each stage is described more fully and several possible writing tasks for this stage are suggested.

\section{First stage:}

The early stages of writing often don't look like writing. Instead these are often the conversations in which the student and his/her advisor explore research foci and scope. In this stage, the planning for the research begins. Perhaps some scheduling takes place. The student begins to read relevant literature. This early stage is critically important to successful writing because many writing problems can be traced to uncertainty in focus, too large a scope, and/or not enough precise information. Moreover, even though the earliest stages of research may not be characterized by writing, writing tasks at this stage often ensure successful thesis preparation many months later. In addition, early writing can allow the advisor to "see" the student's level of critical thinking as well as the student's writing abilities.

Suggested writing tasks in the first stage

- In this first stage, when the student and advisor are exploring research foci and scope, it's logical for the advisor to ask for a thesis prospectus. Although disciplines vary in their views of what this might encompass, a prospectus could include sections on a

"Proceedings of the 2005 American Society for Engineering Education Annual Conference \& Exposition Copyright $\mathbb{C} 2005$, American Society for Engineering Education” 
statement of topic; the background and significance of the research problem; the scope of research; possible sources in the literature; and an estimated schedule of work. A welldone prospectus can act as a cornerstone for the rest of the work, and parts of this can later be revised as the introductory section of the thesis.

- Also in this early stage, an advisor can ask for a literature review. At this stage, the student is likely to be deeply involved in searching the literature since much of his/her research method will be informed by previous work. A solid critical review of the literature is well within the student's ability quite early in the process. If a literature review is not feasible, then the student can produce a well-annotated bibliography that will help him/her to write the literature review section later.

- Developing a method for organizing and reviewing student's research notes will also help the student and advisor. Again, this practice helps the advisor track the work the student is doing as well as his/her ability to articulate insights or knowledge in writing. This perspective helps the advisor guide the process and perhaps nearly as importantly, it also serves the purpose of allowing the student to present and then archive interesting but extraneous (to the thesis) material. A cause of a disorganized, too lengthy, and unfocussed thesis is often the inclusion of disparate material that the student wants to present even though it doesn't support or relate to his/her argument.

Second stage:

The first and second stages are usually interactive since research projects often involve re-focus or re-scoping. Also, in the second stage, the student begins focused research: developing methodology, taking data, and analyzing that data.

Writing tasks for the second stage

- Students in the second stage may begin to co-write technical articles with their advisor and/or to present research work at conferences or in workplace reviews. These opportunities help the graduate student articulate his/her work orally and also in writing. These repeated instances help refine the thinking and language and ultimately strengthen the thesis.

- Students in the second stage also may begin to produce substantive drafts of sections of the thesis. In fact, an advisor can facilitate this, suggesting that the student begin with the results section and then proceed to the discussion section and the methodology section. *This sequence is counter-intuitive for students, generally. Many inexperienced writers will begin writing the thesis the chronological way that the project evolved or in the way that they imagine the reader will read it (beginning to end). And for most students, what are more interesting at this stage are the results/discussion and then the methodology sections. The questions "what have you found?" and "what do you think it means?" and "how did you get this result?" are at the heart of all research. They require a substantial amount of energy and thought to answer, but they are perhaps the sections in which the student is most invested and interested.

\footnotetext{
* Professor Stephen Hall, MIT, personal communication, 12-1-04

"Proceedings of the 2005 American Society for Engineering Education Annual Conference \& Exposition Copyright (C2005, American Society for Engineering Education”
} 
- The advisor can also prompt the student to prepare the quantitative graphics that display data but, more specifically, to prepare them separately from textual interpretation. $\delta \phi$ Again, inexperienced writers often struggle with information graphics. Perhaps they think of them as an after thought; perhaps they rely too much on the graphic and do not supply the appropriate interpretation; perhaps the useful graphic is inserted too far from the discussion; perhaps the graphics are not the appropriate ones for the work and simply the ones that the software produces. In any case, what Poe and Freeman ${ }^{\phi}$ call "the story of data" is a graphical way to help students build the results and discussion section. Well-designed graphics that display reduced data are an elegant, precise form of communication. Partnered with the necessary concise interpretation, they anchor the thesis.

Experienced advisors quickly see that at this point and using this model, the student has completed the essential sections of the thesis. S/he has completed the results/discussion and the methodology sections complete with graphics. S/he has already written a sound draft of the literature review or at the very least the material archived in an annotated bibliography. The prospectus can provide an early draft of the introductory section of the thesis. The student adds a conclusion and an abstract, and the thesis is largely complete.

The third stage is often what graduate students and advisors mean by writing. In this usually unsuccessful, "back loaded" model, a great deal of writing takes places at the end of the thesis project while the student is simultaneously correcting and revising the language as well as formatting the document. Using the model suggested here can substantially reduce the stress and inevitable frustration of this stage. If a student has been producing writing at all stages of the research, there is usually a final draft ready for technical review by the advisor.

When the document is in a final draft form and technically correct, then the writer can turn his/her attention to producing a professional document for submission. These final tasks are not a substitute for the writing tasks tackled earlier in the thesis process. However, if those stages have produced substantial drafts, then the last tasks are usually quickly managed.

It's worth noting that most inexperienced writers will need to devote some time to corrections. While experienced writers may able to attend to both the articulation of the idea itself as well as the language on the page, many writers will find that complex critical thinking draws their attention from sentence level correctness. This is, in itself, not a problem as long as planning has provided enough time to correct and to revise.

Writing tasks for the third stage:

- A student may produce several revisions for his/her advisor.

\footnotetext{
${ }^{\delta}$ Professor Charles Oman, MIT, personal communication, 12-1-04

${ }^{\phi}$ Poe, Mya and Dennis Freeman, MIT, unpublished work

$\phi$ Poe, Mya and Dennis Freeman, MIT, unpublished work

"Proceedings of the 2005 American Society for Engineering Education Annual Conference \& Exposition Copyright (C2005, American Society for Engineering Education”
} 
- This is the stage for final corrections of the language: spelling, punctuation, and grammar.

- This is also the stage for the final formatting of the document: adding the navigational structure, labeling graphics, producing a thorough list of sources cited, adding necessary appendices and acknowledgements.

- Proofreading is the last task.

\section{The effective, efficient use of advisor time:}

The model suggested here allows the advisor to be more effective because s/he concentrates on what $\mathrm{s} / \mathrm{he}$ does best and prefers to do: guide research projects to completion. The model uses the advisor's time more efficiently because it distributes the writing work of the thesis over the time period of the project and rests it more solidly on the student's shoulders. Because the writing tasks are linked to cognitive tasks and because the model allows plenty of time for drafts of sections, the final draft should bewhen the advisor sees it - a sound draft.

\section{International students or poorly prepared students}

But what about writers who do not have basic writing skills or has an international language background? When the student writer is impaired in some way by poor undergraduate preparation, the useful solution is to provide the writer with the resources necessary to support the thesis effort. Most universities have a writing center that provides these resources, but some advisors and students may need to search for these resources.

If the writer is an international student, s/he may need different resources. A student may be an excellent writer in his/her first language and may speak American English well and even be able to write a short admission essay but still have difficulty adapting to the rhetorical style and grammatical structures of complex academic prose.

Thus resources that target problems with basic writing or with American English syntax are often useful to student writers. However, even inexperienced, poorly prepared, or international writers still improve when the basic principles of learning to writing well are applied: writing requires practice; writing requires successive iterations; writing tasks are most efficient when linked to the current cognitive task of the writer.

\section{Conclusion}

Most academic and technical writing can be accomplished successfully and efficiently by using a practice-based model that includes drafts and revisions that are written over the life of the project. This model can be scaled down to support undergraduate capstone or design projects as well as larger, complex thesis preparation. Although many advisors will still comment knowledgeably on the actual writing of the thesis, it is hoped that the use of this suggested model would allow them to devote their attention to the substance of the research project. 


\section{Biographical Information}

JENNIFER L. CRAIG is a Lecturer in Communications in the MIT Department of Aeronautics and Astronautics and the Program in Writing and the Humanities. Her previous appointment was at the University of Maine, Orono in the Department of English where she taught technical writing and worked collaboratively with the Department of Computer Science and several departments within the College of Engineering. She holds an M.S. from Simmons College and an M.A. from the University of Maine. 